\title{
The FiguRATIVE DimENSION OF Welsh NiCKNAMING IN THE LIGHT OF THE GREAT CHAIN OF BEING
}

\author{
KATARZYNA JĘDRZEJEWSKA-PYSZCZAK
}

\section{Introduction}

This paper aims to set the analysis of contemporary Welsh nicknames in the context of

a) The cognitive view of metaphor and metonymy and

b) The cultural conception of the Great Chain of Being.

Firstly, the historical background of nickname formation in Wales is outlined. Secondly, a cognitive approach to the notions of metaphor and metonymy is briefly discussed with special reference to the classinclusion model postulated by Glucksberg and Keysar (1990). Thirdly, the concept of the Great Chain of Being and its implications for the study of Welsh nicknames are introduced. Lastly, instances of metaphorical and metonymic Welsh nicknames are addressed as reflecting the natural hierarchy of life forms conceptualised in the Great Chain of Being. The corpora of Welsh nicknames are mainly based on Myrddin ap Dafydd's (1997) Llysenwau: Casgliad o lysenwau Cymraeg a gofnodwyd yn y cylchgrawn Llafar Gwlad 'Nicknames: Collection of Welsh nicknames which were recorded in the journal Llafar Gwlad' as well as Roy Noble's (1997) Welsh nicknames for contemporary nicknames only. Also, Welsh popular periodicals such as Llafar Gwlad and Country Quest proved useful.

\section{A short history of nicknaming in Wales}

The popularity of nicknames in Wales takes root at the time of the Renaissance, even though already in the ancient stories of the Mabinogi a change of name based on individual peculiarity comes as no surprise. In the tale of Pwyll Prince of Dyfed, a lost boy was first called by his guardian Gwri Wallt Euryn 'Gwri Gold Hair' due to his appearance and was later renamed Pryderi 'Anxiety' on being returned to his mother as:

"I declare to heaven," said Rhiannon, "that if this be true, there is indeed an end to my trouble." "Lady," said Pendaran Dyved, "well hast thou named thy son Pryderi, and well becomes him the name of Pryderi son of Pwyll Chief of Annwvyn."

"Look you," said Rhiannon, "will not his own name become him better?" "What name has he?" asked Pendaran Dyved. 
"Gwri Wallt Euryn is the name that we gave him." "Pryderi," said Pendaran, "shall his name be." "It were more proper," said Pwyll, "that the boy should take his name from the word his mother spoke when she received the joyful tidings of him."

And thus it was arranged (The Mabinogion, 14-15).

Fixed surnames as a direct influence of the Anglo-Norman conquest produced a Welsh surname system that was patronymic in nature: it entailed the addition of the particle $a p$ (before a consonant) and $a b$ (before a vowel $)^{1}$ - abbreviated form of the word mab 'son' usually followed by the father's (or other ancestor's) name - to the baptismal name. In a similar vein, married women usually retained their patronymic; metronymic patterns were highly exceptional in Welsh, yet not nonexistent, as in Gwladus uch Morgan 'Gwladus the daughter of Morgan' or Lleucu uch Gruffudd 'Lucy the daughter of Griffith' where uch and ach were abbreviations for ferch 'the daughter of'. Morgan and Thomas believe that the patronymic system in Wales "reflected the clear distinction the Welsh then had (and still have) between surnames and nicknames, a strong sense of kinship and perhaps the lack of a sense of individualism" (Morgan \& Thomas 1984: 232).

Bishop Rowland Lee, (1487-1543), president of the Council of Wales at the time of the Welsh-English Union, has been famously credited with imposing the first fixed Welsh surname of Mostyn upon Rhisiart ap Hywel of Mostyn (the influential relative of the Tudor dynasty), yet several Welsh families living along the Welsh-English border are recorded to have adopted fixed surnames as early as the fifteenth century. In fact, it were the anglicised Welsh gentry that initiated the process on a large scale. In rural areas the process had a much slower pace and came to a halt as late as the mid-nineteenth century. The patronymic pattern of naming in Wales suffered from the decay of the native legal system that evolved around the notion of kinship. With the individual and his role in the society on the rise, group and community bonds were easily broken. Current fashion also played a vital part in the narrowing down of the available name stock as few baptismal names became highly conventionalised, leaving almost no room for diversity.

\footnotetext{
${ }^{1}$ This is a simplified version of the rule and, as Morgan and Morgan admit, "uncertainty remains about the use of $a b$ and $a p$ in certain other contexts" (Morgan \& Morgan 1985: 10). Nevertheless, the general assumption, although true with regard to the twelfth century, that $a b$ preceded vowels and voiced consonants and $a p$ voiceless consonants (Williams 1975: 112), cannot be borne out by evidence from later centuries.
} 
After the Acts of Union (1536 and 1543) English clerks, unfamiliar with the intricacies of the Welsh language, ruthlessly transcribed Welsh patronymics in the English manner. The old names of Celtic origin were either anglicised, e.g. Dafydd-David, Gruffudd-Griffith, or substituted by biblical or royal ones, e.g. John, David, Henry or Richard (cf. Stephens 1986: 567). In effect, numerous families bore the same surname. With the obscured recognition and identification that followed the Welsh resorted to the coinage of nicknames in the face of the striking paucity of unambiguous means of reference. The Welsh inclination towards nicknames, at the expense of adopting surnames, can also be explained in pure psychological terms, as marked by Parry-Jones: "I have said that the Welsh had little use for surnames - that is an understatement. In the countryside, there survives a tenacious objection to them, possibly an inherited consciousness of the fact that they were foisted upon us by judges in English courts" (Parry-Jones 1949: 51).

\section{A cognitive view of metaphor and metonymy}

A classical view of metaphor claims that metaphors are artifacts of language use with no relation to meaning or understanding. Moreover, they are said to arise from objective similarity. ${ }^{2}$ Thus, we can speak of "digesting an idea" because the mental action of attending to the expression of an idea, reasoning about it and coming to understand it is objectively similar to the physical action of ingesting food, breaking it into nutrients and absorbing them into the system. Lakoff and Johnson (1980) argue against this idea of a priori similarity. They insist that metaphors create similarities, instead of simply pointing them out. ${ }^{3}$

Lakoff and Johnson shift focus towards ways of organising our experience by claiming that we do not need to postulate an inherent similarity between two concepts, because the metaphorical organisation of our perception and understanding is systematic. Subsequently, "the essence of metaphors is understanding and experiencing one kind of thing in terms of the other" (Lakoff \& Johnson 1980: 9), e.g. TIME IS MONEY, EMOTIONAL HURT $=$ PHYSICAL HURT or IDEAS ARE FOOD. What Lakoff and Johnson also noticed is the presence of a single underlying

\footnotetext{
${ }^{2}$ Kuryłowicz (1970: 135) provides the following definition of a metaphor: "A linguistic form B is a metaphor of a linguistic form A, if it is associated with $\mathrm{A}$ owing to the SIMILARITY of the respective referents and used to denote the referent of A".

${ }^{3}$ As it is the Lakoffian approach that has become increasingly influential, it will provide the point of departure of the current work.
} 
metaphor behind whole clusters of expressions as in the LOVE IS A JOURNEY cluster, e.g. Look how far we've come, We're at the crossroads, It's been a long, bumpy road or This is a dead-end relationship. However, this does not enable us to understand all aspects of one concept in terms of the other as some aspects are hidden, e.g. time cannot be taxed or passed on to our children, while others are highlighted (cf. Lakoff \& Johnson 1980, Kövecses 2002). Hence, metaphorical correspondences are always partial. It is further supported by the Invariance Principle which allows only as much knowledge from the source domain to be transferred onto the target domain as guarantees a non-violation of the image-schematic properties of the target.

A metaphor in the cognitive view involves systematic correspondences (mappings) from a source (or donor) domain to a target (or recipient) domain, where the former represents familiar and mundane experiences while the latter draws on abstract concepts and socially constructed phenomena. Entailments from the source domain are used to reason about the target domain. The selection of source domains, i.e. the experiential basis or motivation of metaphors ${ }^{4}$, is conditioned by everyday interactions. Both domains, however, cannot be part of the same superordinate domain (cf. Barcelona 2000: 3).

Apart from Lakoff and Johnson's ground-breaking work, a number of theories of metaphor have been propounded. The class-inclusion model (cf. Glucksberg \& Keysar 1990), favoured in this paper, construes the source of the metaphor as a prototypical member of an ad hoc created superordinate category that also encompasses the target. For this reason the source is simultaneously treated as an exemplar of this category. Systematic mappings are not required of the source and target as the presence of one salient property suffices to establish a link.

The following analysis of metaphorical uses nicknames embraces the class-inclusion approach so as to account for the disregard for all the other properties but the one that underlies the choice of an alternative personal designation. ${ }^{5}$

The traditional definition of a metonymy, i.e. $\mathrm{X}$ stands for $\mathrm{Y}$ indicates a relation of substitution. Metonymy studied from the cognitive perspective is defined as a "process in which one conceptual entity, the

\footnotetext{
${ }^{4}$ As Kövecses (2002: 69) notes: "conceptual metaphors are based on a variety of human experience, including correlations in experience, various kinds of non-objective similarity, biological and cultural roots shared by two concepts, and possibly others".

${ }^{5}$ The underlying origin of nickname coinages is based entirely on available compilations as included in the primary sources.
} 
vehicle, provides mental access to another conceptual entity, the target, within the same idealized cognitive model" (Radden \& Kövecses 1999: 21) or, as Seto (1999: 91) has it, "a referential transfer phenomenon based on the spatio-temporal contiguity as conceived by the speaker between an entity and another in the (real) world". Subsequently, it is the first category that is given prominence. Kosecki $(2005: 21)$ assumes it to be a highly structured mechanism based on association and (physical or conceptual) contiguity that underlies numerous linguistic operations ranging from semantic change and pragmatic inferencing to the structure of categories and signs and word formation. Despite the alleged prevalence of metonymy as the "fundamental and over all phenomenon" (Kuryłowicz 1970: 136), some scholars (cf. Bredin 1984, Barcelona 2000, Ibánez 2000) claim metonymic models have not been as extensively studied as metaphorical constructions.

Lakoff and Johnson (1980: 38-39) enumerate ten metonymic models that are to be treated as "representative examples", namely:

(1) FACE FOR PERSON (We need some new faces around here),

(2) CONSUMED GOODS FOR CUSTOMER (Are you the baked beans on toast?),

(3) BODY PART FOR PERSON (There are a lot of good heads in the university),

(4) PART FOR WHOLE ${ }^{6}$ (That's a nice set of wheels),

(5) PRODUCER FOR PRODUCT (I have a Ford),

(6) OBJECT USED FOR USER (The sax has the flu today),

(7) CONTROLLER FOR CONTROLLED (The buses are on strike),

(8) INSTITUTION FOR PEOPLE RESPONSIBLE (The Senate thinks abortion is immoral),

(9) PLACE FOR INSTITUTION (Wall Street is in a panic),

(10) PLACE FOR EVENT (Watergate changed all our politics).

The set does not by any means aspire to be exhaustive and a plethora of additional metonymic representations can be found elsewhere, e.g.

\footnotetext{
${ }^{6}$ As Radden and Kövecses (1999: 31) remark, the term synecdoche is commonly employed to refer to part for whole metonymies, hence indicating a separate class in its own right. A dictionary definition of a synecdoche entails a distinction between a particularising synecdoche (reference by means of a semantically narrower term, as in part for whole or the specific for the general) and a generalising synecdoche (application of a broader term, as in the whole for part) (cf. Bussmann 1996: 470). For details on the metonymy-synecdoche relationship, see Seto (1999).
} 
(a) AUTHOR FOR WORK (She loves Picasso),

(b) RESULT FOR ACTION (to beautify the lawn),

(c) EFFECT FOR CAUSE (Don't get hot under the collar),

(d) MATERIAL FOR OBJECT (I sent you an e-mail) or

(e) DESTINATION FOR MOTION (to porch the newspaper),

to mention but a few. In contrast to metaphor, metonymy usually allows for bidirectional mappings as in

(1) CONTAINER FOR CONTENTS (I'll have a glass) vs. CONTENTS FOR CONTAINER (The milk tipped over),

(2) SPECIES FOR GENUS (to earn one's daily bread) vs. GENUS FOR SPECIES (readable) or

(3) PLACE FOR INHABITANTS (The whole town voted for the Mayor) vs. INHABITANTS FOR PLACE (The Russians hosted the Eurovision Song Contest).

\subsection{Metaphor and metonymy overlap}

Metaphor and metonymy are generally perceived as diverse cognitive mechanisms as they function along the lines of similarity/comparison and contiguity/nearness/neighbourhood respectively. Thus, according to Bredin (1984: 44), metaphor can be said to create a relation between its objects, while metonymy presupposes it. Additionally, the difference lies in the direction of the mapping: metaphors involve correspondences across different cognitive models, while metonymy operates within a single model. Metaphorical expressions rely on contradictory experiential domains in the sense that one domain typifies abstractions whereas the other utilizes concrete concepts. In metonymy, the reality of one conceptual space determines a closer relation between its underlying elements, even though the dichotomy abstract vs. concrete may still hold, reducing considerably the internal distance between the two notions. Kövecses (2002: 147-8) goes as far as stating that while understanding may indeed be the main aim of a metaphorical formation, a metonymic construction is predominantly concerned with affording mental access to a target.

Nevertheless, it has been acknowledged (cf. Goossens 1990, Ungerer \& Schmid 1996, Black 1962) that metonymy and metaphor are involved in processes of interaction where the boundaries between the two figurative phenomena are often blurred. ${ }^{7}$ Traces of such connections can

\footnotetext{
${ }^{7}$ Already Lakoff and Johnson (1980: 37) laid the foundations for such investigations by touching upon the sameness of purpose and manner as shared by metaphor and metonymy.
} 
be seen in linguistic expressions such as to be close-lipped or to shoot one's mouth off where the former exemplifies the case of metaphor from metonymy while the latter employs metonymy within metaphor (Kövecses 2002: 160-161). Radden (2000: 93) admits that the distinction between metaphor and metonymy is "notoriously difficult, both as theoretical terms and in their application... it is often difficult to tell whether a given linguistic instance is metonymic or metaphorical". His enumeration of four types of metonymy-based metaphors leads him to the conclusion that the metaphor-metonymy transition is a common occurrence. Likewise, Ibánez (2000) observes the apparent similarity between metonymic mappings and those of "one-correspondence" metaphors.

\section{The Great Chain of Being}

From the time of the ancient Greeks, it has been a commonplace to think and write about life forms as if they were part of a linear hierarchy. The medieval cultural conception of such a natural hierarchy is known as the Great Chain of Being. Yet, the concept seems to be of significance as Lakoff and Turner (1989: 167) remark: "it still exists as a contemporary unconscious cultural model indispensible to our understanding of ourselves, our world, and our language". In the basic version of the Great Chain of Being it is the humans who occupy the top position within the hierarchy of life forms. The extended version of the concept assumes God to be the ultimate being. Arthur O. Lovejoy (1963) identifies three basic intellectual components of the Great Chain of Being. The Principle of Plenitude focuses on the diversity of species as exemplars of God's bounty. The Principle of Continuity, on the other hand, ascertains that species blend into one another with no unbridgeable gaps separating them. The Principle of Gradation holds that there exists a scale from the lowest type(s) of existence to the highest form.

Krzeszowski (1997: 68) presents the Great Chain of Being, together with the corresponding hierarchy of properties for each level, as follows:

\section{Being}

(A) GOD

(B) HUMANS

(C) ANIMALS

(D) PLANTS

(E) INORGANIC THINGS

\section{Mode of existence}

being in itself

spiritual

animate

vital

physical
The highest property

divinity reason/soul

instincts

life

material substance 


\subsection{Reflection of the principle of gradation in Welsh nickname formations. Metaphorical expressions}

(E) INORGANIC THINGS

- Over-representation of form:

Pots - The underlying metaphor:

Pot $\left(\right.$ Source) $\rightarrow$ Implicit nicknamee $^{8}$ (Target)

Entailment: The shape of the source is projected onto the target's appearance, so as to stress the latter's shortness and roundness.

Huw Hanner Mast 'Huw Half Mast' - The underlying metaphor:

Half Mast (Source) $\rightarrow$ Explicit nicknamee Huw (Target)

Entailment: The dressing style of the target evokes direct associations with the source - trousers ending before the ankle resemble half folded sail on a mast.

Spike - The underlying metaphor:

Spike (Source) $\rightarrow$ Implicit nicknamee (Target)

Entailment: The length of the source is mapped onto the target with a view to underlining the size of the nicknamee.

- Physical potential:

Bella Blue Balls - The underlying metaphor:

Ball (Source) $\rightarrow$ Explicit nicknamee Bella (Target)

Entailment: The target's eyes evoke associations with balls due to their shape.

- Refinement of form:

Coesau Bwrdd 'Table Legs' - The underlying metaphor:

Table legs (Source) $\rightarrow$ Implicit nicknamee (Target)

Entailment: A comparison to table legs is intended to accentuate the shapely limbs of the target (as they are so straight).

$Y$ Geiriadur Mawr 'The Big Dictionary' - The underlying metaphor:

Dictionary (Source) $\rightarrow$ Implicit nicknamee (Target)

Entailment: The notion of possessed knowledge is the element that binds the source and the target.

\footnotetext{
${ }^{8}$ Implicit nicknamee is to be understood as the nickname bearer whose original designation (first name or, rarely, surname) does not form part of the nickname, whereas in the case of explicit nicknamee official name is augmented by means of an accompanying epithet.
} 
- Coarseness of form:

Ned Pot Jam - The underlying metaphor:

Pot (Source) $\rightarrow$ Explicit nicknamee Ned (Target)

Entailment: The thickness of a pot's glass is projected onto the target's glasses.

Fanny Spare Parts - The underlying metaphor:

Spare Parts (Source) $\rightarrow$ Explicit nicknamee Fanny (Target)

Entailment: The randomness of sets of spare parts exemplifies a lack of aesthetics in the target's choice of clothes.

Ken Custard - The underlying metaphor:

Custard (Source) $\rightarrow$ Explicit nicknamee Ken (Target)

Entailment: The mapping for the metaphor is based on the physical feature of source (and more specifically its consistency) that is meant to indicate the sneezing affliction of the target.

Jimmy Candles - The underlying metaphor:

Explicit nicknamee Jimmy (Target) $\rightarrow$ Candle (Source)

Entailment: The sorry sight of the target's runny nose conjures up a picture of a burning candle.

\section{(C) ANIMALS}

\section{- Over-representation of form:}

Trwnc 'Trunk', Bil Parot 'Bil Parrot' - The underlying metaphor:

Trunk/Parrot (Source) $\rightarrow$ Implicit nicknamee/Explicit nicknamee Bil (Target)

Entailment: The sizes of nicknamees' noses are highlighted by matching them to an elephant's trunk and a parrot's beak respectively.

Egg on Legs - The underlying metaphor:

Egg (Source) $\rightarrow$ Implicit nicknamee (Target)

Entailment: The shape of an egg, and more specifically its roundness and shortness, serves as an apt characteristic of the target.

- Natural resilience:

Yr Arth 'The Bear' - The underlying metaphor:

Bear (Source) $\rightarrow$ Implicit nicknamee (Target)

Entailment: The mapping between the source and the target operates along the lines of impressive stature and unmatched physical strength as both features characterize the animal. 
Conger - The underlying metaphor:

Conger (eel) (Source) $\rightarrow$ Implicit nicknamee (Target)

Entailment: The inherent feature of the source, i.e. its slipperiness, is mapped onto the sphere of the target's relations with the outside world.

- Instinctive behaviour:

Ian Ci 'Ian Dog' - The underlying metaphor:

Dog (Source) $\rightarrow$ Explicit nicknamee Ian (Target)

Entailment: Lecherous behaviour of the target is explained through biological conditioning of the source.

Huw Ddyfrgi 'Huw the Otter' - The underlying metaphor:

Otter (Source) $\rightarrow \quad$ Explicit nicknamee Huw (Target)

Entailment: Swimming prowess as an inherent quality of the source and the target.

Hedydd 'Lark' - The underlying metaphor:

Lark (Source) $\rightarrow$ Implicit nicknamee (Target)

Entailment: The target's preoccupation with whistling is reflected through the prism of the source's incessant singing. Additionally, the mapping suggests a similar artistic par.

Seagull - The underlying metaphor:

Seagull (Source) $\rightarrow$ Implicit nicknamee (Target)

Entailment: Insatiable appetite as the defining feature of the source and the target.

\section{(B) HUMANS}

- Individual diversity:

Chinc 'Chinese'/Joni Jap - The underlying metaphor:

Inhabitant of China/Japan (Source) $\rightarrow$ Implicit/Explicit nicknamee Joni

Entailment: Squinted eyes as the source for the mapping.

Bob Doctor - The underlying metaphor:

Doctor (Source) $\rightarrow$ Explicit nicknamee Bob (Target)

Entailment: Target's knowledge of medical affairs is believed to equal that of an educated man of the profession.

- Awkwardness of style:

Robin Soldiwr 'Robin Soldier' - The underlying metaphor:

Soldier (Source) $\rightarrow \quad$ Explicit nicknamee Robin (Target)

Entailment: A military walking style is mapped from the source onto the target. 
Annie Dyn 'Annie Man' - The underlying metaphor:

Man (Source) $\rightarrow \quad$ Explicit nicknamee Annie (Target)

Entailment: Male features dominate over the target's biological gender.

- Resistance to unfavourable conditions:

Baban 'Baby' - The underlying metaphor:

Baby (Source) $\rightarrow$ Implicit nicknamee (Target)

Entailment: Young looks of the target, despite its being advanced in years, are implied by the choice of the source.

Amazon - The underlying metaphor:

Amazon (Source) $\rightarrow \quad$ Implicit nicknamee (Target)

Entailment: The target and the source are similar in terms of displayed female defiance.

Morgan the Lawyer - The underlying metaphor:

Lawyer (Source) $\rightarrow \quad$ Explicit nicknamee Morgan (Target)

Entailment: The nicknamee exemplifies a sense of infallibility, characteristic of lawyers.

\subsection{Reflection of the principle of gradation in Welsh nickname formations. Metonymic expressions}

(E) INORGANIC THINGS

- Item of clothing for person:

John Bais 'John the Petticoat',

Ned Trowsus Gwyn 'Ned White Trousers',

Tomi Crys Glan 'Tomi Clean Shirt'

Additionally, the nickname Patchy represents a metonymic chain ${ }^{9}$, i.e.

- Material for item/Item for person

Patchy (teacher who always wears patches on his jacket).

- Accessory for person:

John the Box, Dai Cube, Dai Book and Pencil, Wigs, Iwan Ring, Jac Sebon 'Jac Soap', Bob y Sgidie 'Bob the Shoes'.

\footnotetext{
${ }^{9}$ In metonymic chains the first source of the chain entails a further succession of metonymies so as to arrive at a proper understanding of an utterance (double metonymy, multiple metonymy).
} 
Types of accessories are mostly connected with the nature of work as well as appearance/habit:

- Place of work/Institution for person:

Ysbyty Ifan 'Hospital Ifan', Jones y Siop 'Jones the Shop',

Shoni Ben Pwll 'Shoni Top Pit' (it refers to the part of the mine just above the ground).

- Object for place/Place for person as a metonymic chain:

Gwilym Lampy (one who worked in the lamp-room on top pit)

- Controlled for controller:

Dei Banjo, Ffani Ffidil 'Ffani Violin', Dai Grass (one who worked as a groundsman), Stan the Can (one who recycled cans), Tommy One tune, Jimmy Small Coal (one who collected small coal), Willie Three-Piece (one who worked for a furniture firm).

- Material for object/Controlled (object) for controller as a metonymic chain:

Johnny Skins (one who plays the drums).

- Place for inhabitant:

Bob Llawr 'Bob Downstairs',

Bob Lloft 'Bob Upstairs',

Mrs. Jones Cornerhouse

- Number for place/Place for inhabitant as metonymic chains:

Huw Bach 13 'Little Huw 13' (Huw who lived under number 13),

Rhen Bedwar 'Rhen the Four' (Rhen who lived under the number 4)

- Material for object/Place for person:

Dai Bricko (one who lived in a house made of brick)

- Product sold for seller:

Jones y Bara 'Jones the Bread',

Dafydd Menyn 'Dafydd Butter',

Roberts Sand y Môr 'Robert Sand of the Sea'

(one who sold sand from the sea) 
(B) HUMANS

- Body part for person:

Dafydd Talcen 'Dafydd Forehead',

Goronwy Fochau 'Goronwy the Cheeks',

Llinos Bengoch 'Llinos the Red Head',

Wil Pen Cam 'Wil Crooked Head',

Aled Pen Fflat 'Aled Flat Head',

Miss Williams Gwallt Gwlyb 'Miss Williams Wet Hair',

Drip Nos 'Runny Nose'

- Utterance for Person:

Ydy Ydy 'Yes Yes',

Dai Sybstanshal 'Dai Substantial',

Jack Catch $\mathrm{Me}$,

Dai Pretty Trousers,

Herbie Good Boy,

Annie Walk Nicely

\section{- Activity for person:}

Sack-em Jack (one who ruthlessly sacked his employees),

Billy Shake-um (clock and watch repairer who would shake that watch),

Billy Cash Down (one who purchased everything with cash),

Mrs Noddy (old lady who agreed with everyone and nodded),

Dai Look-up (pigeon fancier)

\section{Conclusion}

Welsh nickname formations are ripe in both metaphorical and metonymic expressions. The theory of the Great Chain of Being and its principle of gradation allows to investigate the stock of nicknames and classify them according to the source of inspiration (external motivation) into those driven by inanimate elements of material world (the basic form of existence), through the more elaborate animal world and, finally, the highest form of existence as shown by examples from the human world.

Welsh nicknames are characterised by metaphorical entailments that allude to over-representation, refinement and coarseness of physical form as well as awkwardness of style, individual diversity, natural resistance or instinctive behavior. Sources domains are derived from the three areas (levels on the ladder of life forms), namely inorganic things, animal world and human world. Mappings that mention refinement of form rely on concepts that appear in the material world. Coarseness of form, on the other hand, is believed to occur among animals and physical 
objects. Associations connected with the human body revolve around the notion of mortality, while natural resilience and resistance to unfavourable conditions are typical of animals and humans respectively. What is more, God's creatures are also perceived as instinct-driven via unpredictability and instability of manner. Individual diversity is nevertheless best exemplified by reference to other human beings.

The class-inclusion model of metaphor, adopted in the investigation, focuses on one salient feature as shared by the source and target. In this sense, it sets aside other possible sources for mappings. What follows is that often it is not the first and most obvious association that is highlighted. The examples of Yr Arth, Ken Custard or Ned Pot Jam well illustrate the point. This clearly shows the unpredictability of metaphorical mapping.

With respect to nicknames, an even greater variety of types is observable. Thus, apart from inorganic metonymic mappings of the (most common) type: ITEM OF CLOTHING/ACCESSORY FOR PERSON one comes across a plethora of other correspondences that include PLACE OF WORK/INSTITUTION FOR PERSON, CONTROLLED FOR CONTROLLER, PLACE FOR INHABITANT Or PRODUCT SOLD FOR SELLER. With respect to "human" mappings, BODY PART FOR PERSON, UTTERANCE FOR PERSON and ACTIVITY FOR PERSON are encountered. The study has not revealed, however, references to either animals or plants as the source of nickname inspiration. Moreover, a preference for simple mappings instead of elaborate metonymic chains is striking.

Further investigation is envisaged to study the above mentioned patterns in detail, especially as an attempt to discern preferences for mappings in Welsh nicknames (e.g. the human and animal world) together with noticeable disregard for others (e.g. the world of plants or God).

An analysis of what features of different life forms are utilised as the motivation for nickname formation could also produce promising results.

Adam Mickiewicz University, Poznań

\section{Abbreviation}

The Mabinogion, trans. Lady Charlotte E. Guest, New York (4 ${ }^{\text {th }}$ ed.), Dover Publications, 1997. 


\section{References}

Ap Dafydd, M., 1997, Llysenwau: Casgliad o lysenwau Cymraeg a gofnodwyd yn y cylchgrawn "Llafar Gwlad", Llanrwst: Gwasg Carreg Gwalch.

Barcelona, A., ed., 2000, Metaphor and Metonymy at the Crossroads: A Cognitive Perspective, Berlin: Mouton de Gruyter.

Black, M., 196, Models and Metaphors, New York: Cornell University Press.

Bredin, H., 1984, 'Metonymy', Poetics Today 5, 45-58.

Glucksberg, S. \& Keysar B., 1990, 'Understanding Metaphorical Somparisons: Beyond similarity', Psychological Review 97, 3-18.

Goossens, L., 1990, 'Metaphtonymy: The Interaction of Metaphor and Metonymy in Expressions for Linguistic Action', Cognitive Linguistics 1, 323-340.

Ibánez, F. J.R. de M., 2000, 'The Role of Mappings and Domains in Understanding Metonymy', in Barcelona A., ed., Metaphor and Metonymy at the Crossroads: A Cognitive Perspective, Berlin, 109-132.

Kosecki, K., 2005, On the Part-whole Configuration and Multiple Construals of Salience within a Simple Lexeme, Łódź: Wydawnictwo Uniwersytetu Łódzkiego.

Kövecses, Z., 2002, Metaphor: A Practical Introduction, Oxford: Oxford University Press.

Krzeszowski, T. P., 1997, Angels and Devils in Hell, Warszawa: Wydawnictwo Energeia.

Kuryłowicz, J., 1970, 'Metaphor and Metonymy in Linguistics', Sign, Language, Culture, 135-136.

Lakoff, G., \& Johnson, M., 1980, Metaphors We Live By, Chicago: The University of Chicago Press.

Lakoff, G., \& Turner, M., 1989, More than Cool Reason: A Field Guide to Poetic Metaphor, Chicago: University of Chicago Press.

Lovejoy, A. O., 1999, Wielki Łańcuch Bytu: Studium z dziejów idei [The Great Chain of Being: A Study of the History of an Idea], Warszawa: Wydawnictwo KR.

Morgan, P. \& Thomas, D., 1984, Wales: The Shaping of a Nation, London: David \& Charles.

Morgan, T. J. \& Morgan, P., 1985, Welsh Surnames, Cardiff: University of Wales Press.

Noble, R., 1997, Roy Noble's Welsh Nicknames, Cardiff: Western Mail Books. 
Parry-Jones, D., 1949, Welsh Country Up-bringing, London: Batsford. Radden, G., \& Kövecses, V., 1999, 'Towards a Theory of Metonymy', in Radden G. \& Panther K.U., eds., Metonymy in Language and Thought, Amsterdam: John Benjamin's Publishing Company, 17-59.

Radden, G., 2000, 'How Metonymic are Metaphors', in: Barcelona, ed., Metaphor and Metonymy at the Crossroads: A Cognitive Perspective, 93107.

Seto, K., 1999, 'Distinguishing Metonymy from Synecdoche', in: Radden, G. \& Panther, K. U., eds., Metonymy in Language and Thought, 91-120.

Stephens, M., 1986, The Oxford Companion to the Literature of Wales, Oxford: Oxford University Press.

Ungerer, F., \& Schmid, J. G., 1996, An Introduction to Cognitive Linguistics, London: Longman.

Williams, I., 1975, The Poems of Taliesin, Dublin: Dublin Institute for Advanced Studies. 